\title{
High blood manganese in iron-deficient children in Karachi
}

\author{
Mohammad Ataur Rahman ${ }^{1}$, Bushra Rahman ${ }^{1}$ and Nessar Ahmed ${ }^{2, *}$ \\ ${ }^{1}$ Karachi Institute of Biotechnology and Genetic Engineering, University of Karachi, Karachi, Pakistan: \\ ${ }^{2}$ School of Healthcare Science, Manchester Metropolitan University, Manchester MI 5GD, UK
}

Submitted 19 July 2012: Final revision received 7 February 2013: Accepted 20 February 2013: First published online 27 March 2013

\begin{abstract}
Objective: Dietary Fe deficiency has a high incidence in Pakistani children and may be associated with increased gastrointestinal absorption of trace metals such as Mn. Therefore, children residing in heavily polluted cities like Karachi may be prone to Mn toxicity. The present study investigated blood Mn concentrations in Karachi children of different Fe statuses.

Design: A prospective observational study was conducted where children were classified into different categories of Fe status - normal Fe, borderline Fe deficiency, Fe deficiency and Fe-deficiency anaemia - using WHO criteria supported by measurements of soluble transferrin receptors. Blood Mn was determined for children in each category using graphite atomic absorption spectroscopy.

Setting: Three hospital outpatient departments in Karachi, Pakistan.

Subjects: A total of 269 children (156 males, 113 females) aged 6-60 months from low-income families of Karachi.

Results: Blood Mn concentrations were significantly higher in children with Fe-deficiency anaemia and Fe deficiency compared with those of normal Fe status (both $P<0 \cdot 01$ ). Blood concentrations of soluble transferrin receptors were higher in children with Fe-deficiency anaemia compared with those of borderline or normal Fe status (both $P<0 \cdot 05$ ).

Conclusions: These findings report for the first time high blood Mn concentrations in Fe-deficient children of this age group. There is therefore an urgent need to identify and remove environmental exposure to $\mathrm{Mn}$ in combination with health strategies aimed at eradicating childhood Fe deficiency.
\end{abstract}

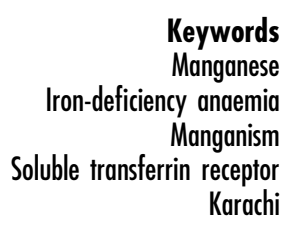

Childhood Fe deficiency is a common nutritional problem affecting some 50-60\% of children aged 6-60 months in various regions of Pakistan ${ }^{(1)}$. The consequences of childhood Fe deficiency include anaemia, reduced work capacity, decreased growth rate, impaired motor development and reduced intelligence quotient scores ${ }^{(2)}$. Fe deficiency is particularly common in the first 2 years of life as children are often weaned on to Fe-deficient diets $^{(3)}$. During dietary Fe deficiency, increased absorption of other trace metals such as $\mathrm{Pb}$ may occur as they often compete with Fe for the same transporters in the mucosal wall ${ }^{(4)}$.

$\mathrm{Mn}$ is an essential trace element and a component of several enzymes including superoxide dismutase. Adults exposed to toxic concentrations of Mn often develop manganism, a neurological condition displaying symptoms similar to Parkinson's disease. Additionally, children exposed to Mn have higher blood and hair concentrations and suffer from a decline in intellectual function ${ }^{(5)}$. Exposure to Mn occurs in steel manufacturing, welding and mining of $\mathrm{Mn}$ ores, and is due to inhalation of Mn-containing dust and fumes ${ }^{(6)}$. Mn is also used in the battery, glass and ceramics industries and is a component of certain pesticides ${ }^{(7)}$. Excessive provision and accumulation of Mn have also been reported in patients receiving total parenteral nutrition, where cholestasis restricts its excretion $^{(8)}$. Mn is present in high concentrations in tea and excessive tea consumption has been associated with its toxicity ${ }^{(9)}$.

An increased absorption of Mn in Fe-deficient subjects may account for the fivefold increase in blood $\mathrm{Mn}$ observed in anaemic individuals aged between 13 and 44 years $^{(10)}$. Strong evidence exists that $\mathrm{Fe}$ and $\mathrm{Mn}$ compete for absorption into the mucosal cells ${ }^{(11)}$. This absorption has been attributed to the divalent metal transporter protein-1 (DMT1) which is a common transporter for both $\mathrm{Fe}$ and $\mathrm{Mn}^{(12)}$. However, transferrin, the major transport protein for $\mathrm{Fe}$, has also been implicated in the transport of $\mathrm{Mn}^{(13)}$. Another study conducted in adults showed those with Fe-deficiency anaemia had significantly higher concentrations of blood Mn compared with controls $^{(14)}$. However, all of these previous studies investigating the relationship between Fe deficiency and blood Mn are either in adults or children over 13 years of 
age. In the present study, we looked at a much younger age group (6-60 months) as these children are more likely to suffer from Fe deficiency. Furthermore, we conducted our study in Pakistan, which has a high incidence of Fe deficiency and where there is very little information on blood $\mathrm{Mn}$ in children and none on its relationship with Fe status. The present study investigated blood Mn concentrations in children from Karachi who were categorized into four groups depending on the severity of their Fe deficiency: normal, borderline Fe deficiency, Fe deficiency and Fe-deficiency anaemia. In the past, many studies determined Fe status using ferritin as a marker. However, it is well known that ferritin concentrations increase in individuals with an acute-phase reaction, as in inflammation, irrespective of Fe status and thus need to be interpreted with caution or supported by markers not influenced by acute-phase reactions such as measurements of soluble transferrin receptors (sTfR). Indeed, in the present study, Fe status was determined using WHO criteria and supported by measurements of sTfR, a sensitive indicator of early Fe deficiency.

\section{Materials and methods}

The study received approval from the Ethics Committees of Kharadar General Hospital, Civil Hospital and Liaquat National Hospital, all in Karachi, Pakistan, as well as the Ethics Committee at Manchester Metropolitan University, UK. The minimum number of children required for each group of $\mathrm{Fe}$ status was determined by power analysis using the UCLA Department of Statistics Power Calculator. This has been determined for expected differences for blood values for Mn.

\section{Study population}

A total of 506 children aged 6-60 months were selected and screened for their $\mathrm{Fe}$ status at paediatric outpatient departments of Karachi Civil Hospital ( $n$ 278), Kharadar General Hospital ( $n$ 73) and Liaquat National Hospital ( $n$ 155). The height and weight of each child were recorded. A questionnaire was used to collect the following information from parents (usually the mother): name of child, sex, age, clinical history, diet up to 24 months of age, any Fe supplementation, family income (in Pakistani rupees; $<$ Rs 6000; Rs 6001-10000; Rs 10001-20000; >Rs 20000) and parental education (none; primary; secondary; intermediate and above). Parents were informed of the study in layman's terms in their native language. Informed consent was obtained from the parents in writing prior to any collection of blood specimens from children.

\section{Specimen collection}

Non-fasting blood $(5 \mathrm{ml})$ was collected by a trained phlebotomist; $1 \mathrm{ml}$ was transferred into a lithium heparin tube for blood Mn determination, $1 \mathrm{ml}$ was transferred into an EDTA tube for a full blood count and $3 \mathrm{ml}$ was transferred to a tube with a blood clotting gel for the remaining tests (C-reactive protein (CRP), bilirubin, Fe, ferritin and sTfR). All specimens for haematology, CRP and $\mathrm{Zn}$ protoporphyrin were analysed immediately in duplicate, whereas blood samples for Mn analyses were stored at $-70^{\circ} \mathrm{C}$. A stool specimen was collected from each child for hookworm analysis.

\section{Exclusion criteria}

Children with a birth weight less than $2.5 \mathrm{~kg}$, those on parenteral nutrition and those suffering from malignancy, renal disease, any acute/chronic illness or major congenital or perinatal complications were excluded, as was any child who had been hospitalized in the previous six months or was receiving any form of Fe supplementation or total parenteral nutrition.

It is well known that certain conditions can affect Fe status/Mn and thus need to be excluded. For example, the acute-phase response can affect markers of Fe status such as ferritin whereas malignancy and renal disease can both cause anaemia. Similarly, children receiving total parenteral nutrition are susceptible to cholestasis and thus may suffer from decreased excretion of $\mathrm{Mn}$ and a build-up of its blood concentration.

Furthermore, any child who tested positive for hookworm infections following stool analysis was also excluded. Those children who were not in these categories had their blood analysed and those with a CRP measurement $>6 \mathrm{mg} / \mathrm{l}$ or cholestasis (conjugated bilirubin $>10 \mu \mathrm{mol} / \mathrm{l}$ ) were also excluded from the study.

\section{Biochemical tests}

Biochemical tests were performed using automated analyses and kit methods. These methods had undergone routine evaluation and quality controls were used with every batch of specimens. Results for a batch were accepted only when controls were within their acceptable limits.

\section{C-reactive protein}

This was determined within an hour of sample collection using the Tina-quant CRP (Latex) immunoturbidimetric assay (Roche Diagnostics, Basel, Switzerland).

\section{Bilirubin}

Total bilirubin and direct bilirubin were determined using a kit method based on the colorimetric reaction of bilirubin with a diazo reagent (Roche Diagnostics).

\section{Full blood count}

A full blood count was determined by automated analysis using a haematology analyser (Nihon Kohden, Tokyo, Japan) and included measurement of red blood cell count (RBC), white blood cell count (WBC), Hb, haematocrit, mean cell haemoglobin $(\mathrm{MCH})$, mean cell haemoglobin concentration (MCHC) and mean cell volume (MCV). 


\section{Iron status}

Serum Fe was determined using a kit method based on the colorimetric reaction of $\mathrm{Fe}$ with FerroZine (Roche Diagnostics). Total iron binding capacity (TIBC) was determined using a colorimetric kit method (Randox Laboratories, Crumlin, UK) and transferrin saturation was calculated using the formula:

$$
\text { Transferrin saturation }(\%)=\text { serum Fe } / \text { TIBC } \times 100 \text {. }
$$

Serum ferritin was measured using the Tina-quant ferritin immunoturbidimetric kit method (Roche Diagnostics).

\section{Soluble transferrin receptors}

This was performed manually using the human sTfR ELISA kit method (BioVendor GmbH, Heidelberg, Germany). The standards, controls and samples made up to a volume of $100 \mu \mathrm{l}$ were incubated in a microplate at $30^{\circ} \mathrm{C}$ with shaking. All the wells were then washed three times with wash solution before adding $100 \mu$ l of conjugate solution (anti-sTfR antibody conjugated to horseradish peroxidase) to each well. The microplates were incubated at $37^{\circ} \mathrm{C}$ for a further hour with shaking before the wells were washed again three times with wash solution. The substrate solution (tetramethylbenzidine) was added $(100 \mu \mathrm{l})$ to each well followed by $10 \mathrm{~min}$ incubation at room temperature. Colour development was stopped by addition of $100 \mu$ l of stop solution $\left(0 \cdot 2 \mathrm{M}-\mathrm{H}_{2} \mathrm{SO}_{4}\right)$ and the absorbance at $450 \mathrm{~nm}$ was read within 5 min using a microplate reader (ELIZA MAT-3000; DRG Instruments GmbH, Marburg, Germany).

\section{Classification of iron status}

Children were divided into four groups of Fe status based on the WHO criteria as described in Table 1 and blood Mn was then determined in each of these four groups.

\section{Blood manganese}

Blood Mn was determined at the PCSIR (Pakistan Council for Scientific and Industrial Research) Laboratories, Karachi, Pakistan. Mn standards were prepared using Spectrosol manganese solution (BDH, Poole, UK) and Seronorm ${ }^{\mathrm{TM}}$ whole blood trace element controls (SERO AS, Billingstad, Norway) were used for quality control purposes. Whole blood or standards $(50 \mu \mathrm{l}$ each) were mixed with $350 \mu \mathrm{l}$ of diluent $(25 \mu \mathrm{l}$ Triton X-100 and $25 \mu$ l of antifoam B emulsion made up to $50 \mathrm{ml}$ in sterile distilled water) in
$1.9 \mathrm{ml}$ acid-washed metal-free microcentrifuge tubes before being transferred into acid-washed auto-sampler cups and loaded onto the auto sampler for analysis using a Zeeman-background-corrected flameless atomic absorption method with a graphite furnace (model Z-8100; Hitachi, Tokyo, Japan).

\section{Statistical analysis}

Statistical analyses were performed using Minitab 16 statistical software. Depending on distribution (AndersonDarling and Kolmorogov-Smirnoff tests), data are presented as mean with standard deviation or as median with interquartile range and were analysed using the $t$ test/ANOVA if normally distributed or the Mann-Whitney/Kruskal-Wallis test if a non-normal distribution. Differences between groups were analysed by converting the data to a normal distribution (if necessary) and using the Tukey post boc test. Data were correlated with Pearson's or Spearman's method depending on distribution. Multiple regression analysis was used with blood $\mathrm{Mn}$ as the dependent variable and factors of Fe status as independent variables. Results were considered significant when $P<0 \cdot 05$.

\section{Results}

\section{Participants' characteristics}

A total of 506 children were screened of whom 269 met the inclusion criteria. These included 113 females (42\%) and 156 males (58\%). The age range of these children was 6-60 months and their mean age was $28 \cdot 1$ (SD 12.5) months ( $n$ 269). The mean height of these children was $82 \cdot 3(\mathrm{SD} 14 \cdot 1) \mathrm{cm}(n 257)$ and their mean weight was $11 \cdot 1$ (SD $6 \cdot 2) \mathrm{kg}(n$ 257). A total of 237 children were excluded from the study, twenty-four of whom had a CRP measurement in excess of $6 \mathrm{mg} / 1$ and faecal samples from two tested positive for hookworm. Basic information on the gender of these children, and their families' ethnic background, education and income, is outlined in Fig. 1.

\section{Blood Mn in children of different ages}

The blood Mn concentrations in children of different ages are shown in Fig. 2. The mean blood Mn concentration for the children included in the study was $3 \cdot 7$ (SD 1.6 ) $\mu \mathrm{g} / \mathrm{dl}$ ( $n$ 269) and the highest concentrations were found in

Table 1 The WHO criteria for classification of children into normal iron status, borderline iron deficiency, iron deficiency and iron-deficiency anaemia

\begin{tabular}{ll}
\hline Fe status & WHO criteria \\
\hline Normal Fe status & Ferritin $>11 \mu \mathrm{g} /$; transferrin saturation $>10 \%$ \\
Borderline Fe deficiency & Ferritin $>11 \mu \mathrm{g} / \mathrm{l}$; transferrin saturation $<10 \%$ \\
Fe deficiency & Ferritin $<11 \mu \mathrm{g} / \mathrm{l}$ normal Hb, MCV and MCH \\
Fe-deficiency anaemia & Ferritin $<11 \mu \mathrm{g} / \mathrm{l}$; low Hb, MCV and MCH \\
\hline
\end{tabular}

$\mathrm{MCV}$, mean cell volume; $\mathrm{MCH}$, mean cell haemoglobin. 


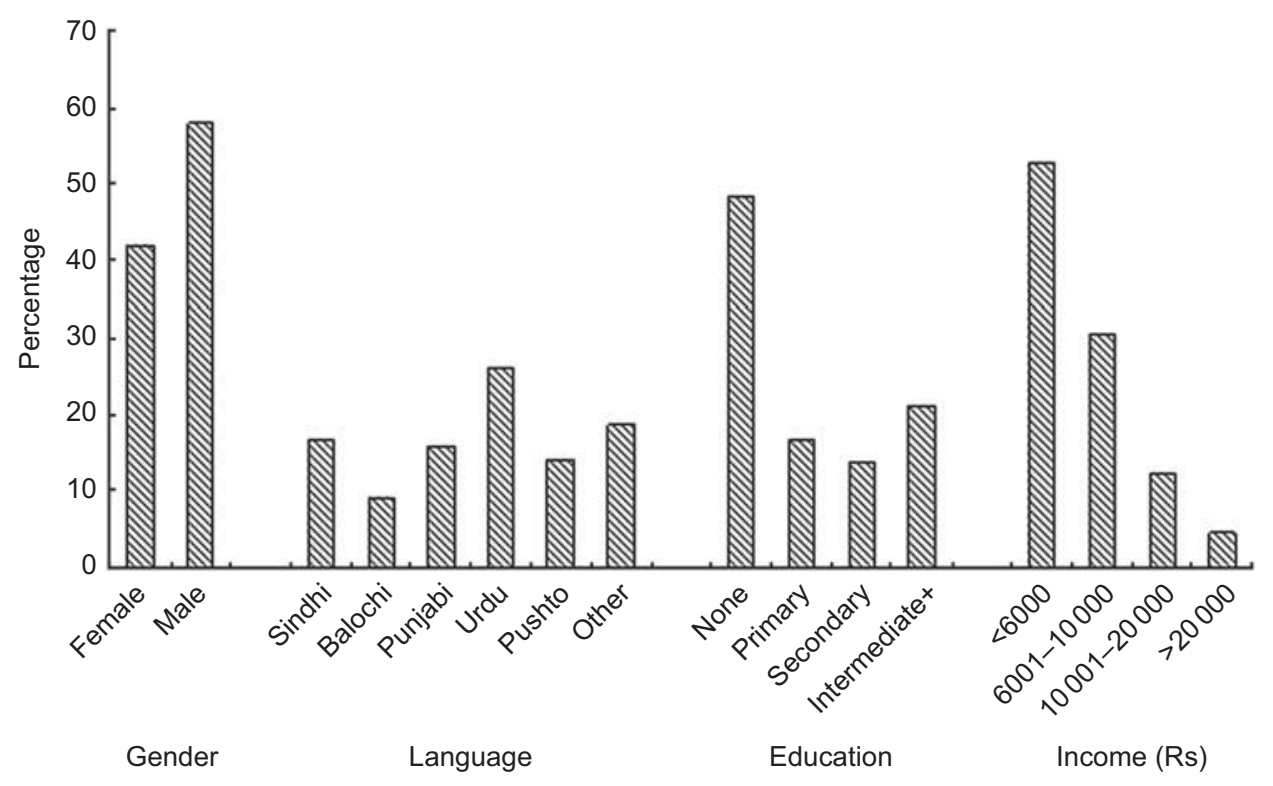

Fig. 1 Participants' gender and the ethnic background, language spoken, education and monthly income (in Pakistani rupees, Rs) of their families: children ( $n$ 269) aged 6-60 months from low-income families, Karachi, Pakistan

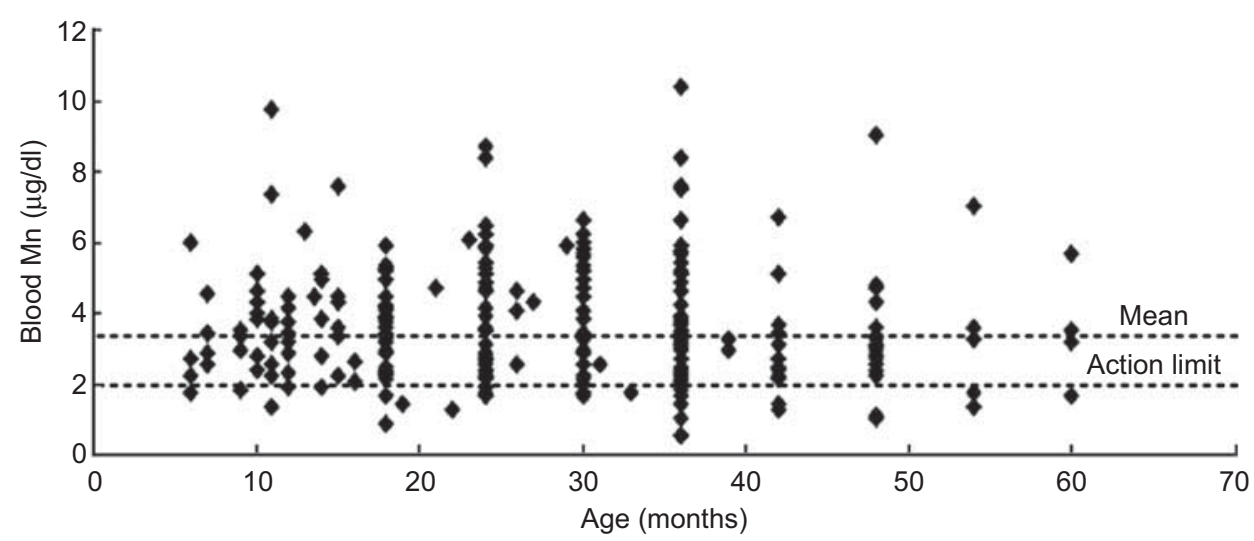

Fig. 2 Scatter plot showing concentrations of blood Mn in the participants according to age: children ( $n$ 269) aged 6-60 months from low-income families, Karachi, Pakistan. Mean blood Mn concentration is 3.7 (SD 1.64) $\mu \mathrm{g} / \mathrm{dl}(n 269)$ whereas the action limit for $\mathrm{Mn}$ is $>2 \cdot 0 \mu \mathrm{g} / \mathrm{dl}$

children in the age range 19-24 months, where the mean was $4 \cdot 0(\mathrm{sD} 1 \cdot 8) \mu \mathrm{g} / \mathrm{dl}(n 43)$.

\section{Blood Mn in children according to Fe status}

Multiple regression analysis showed a weak relationship between $\mathrm{Fe}$ and blood Mn (Table 2). The adjusted $r^{2}$ value showed that the model could explain only $15 \%$ of blood Mn results. In the present analysis, the only independent relationship was Mn with TIBC. In a stepwise regression analysis, ferritin and TIBC had the most significant relationship with $\mathrm{Mn}(P<0 \cdot 001)$.

Blood Mn concentrations were determined following classification of the children into four groups using the WHO criteria, as shown in Table 3. Measurements of sTfR confirmed the Fe deficiency and were a good discriminator of different groups of $\mathrm{Fe}$ status. Indeed, children with Fe-deficiency anaemia had higher sTfR concentrations than those with borderline Fe deficiency or normal Fe status $(P<0 \cdot 05)$. Children with Fe deficiency and borderline Fe deficiency had higher concentrations of sTfR compared with those of normal Fe status $(P<0 \cdot 05)$.

The median blood $\mathrm{Mn}$ concentrations in children with Fe-deficiency anaemia and Fe deficiency were both significantly higher than in the group of children of normal Fe status $(P<0 \cdot 01)$. The median blood $\mathrm{Mn}$ concentration in children with Fe-deficiency anaemia was also significantly higher than that of children with borderline Fe deficiency $(P<0 \cdot 01)$. 
Table 2 Coefficient results for multiple regression analysis with blood manganese as the dependent variable and factors of iron status as independent variables: children $(n$ 269) aged 6-60 months from low-income families, Karachi, Pakistan

\begin{tabular}{|c|c|c|c|c|}
\hline Predictor & Coefficient & SE of coefficient & $t$ & $P$ \\
\hline Constant & $40 \cdot 80$ & $174 \cdot 50$ & 0.23 & 0.82 \\
\hline Haematocrit & $2 \cdot 17$ & $1 \cdot 89$ & $1 \cdot 15$ & 0.25 \\
\hline $\mathrm{Hb}$ & $-7 \cdot 74$ & $5 \cdot 62$ & $-1 \cdot 38$ & 0.17 \\
\hline MCV & $1 \cdot 69$ & $2 \cdot 28$ & 0.74 & 0.46 \\
\hline $\mathrm{MCH}$ & $-5 \cdot 13$ & $7 \cdot 18$ & -0.71 & 0.48 \\
\hline $\mathrm{MCHC}$ & $2 \cdot 41$ & $5 \cdot 70$ & 0.42 & 0.67 \\
\hline $\mathrm{Fe}$ & $0 \cdot 14$ & $0 \cdot 12$ & $1 \cdot 13$ & 0.26 \\
\hline TIBC & $0 \cdot 17$ & 0.082 & $2 \cdot 12$ & 0.04 \\
\hline Transferrin saturation & -0.08 & $0 \cdot 14$ & -0.59 & 0.55 \\
\hline Ferritin & $-0 \cdot 15$ & 0.09 & $-1 \cdot 70$ & 0.09 \\
\hline
\end{tabular}

MCV, mean cell volume; $\mathrm{MCH}$, mean cell haemoglobin; MCHC, mean cell haemoglobin concentration; TIBC, total iron binding capacity.

Table 3 Blood manganese and sTfR concentrations by categorization into normal iron status, borderline iron deficiency, iron deficiency and iron-deficiency anaemia according to the WHO criteria: children ( $n$ 269) aged 6-60 months from low-income families, Karachi, Pakistan

\begin{tabular}{lcccc}
\hline & Normal Fe status & Borderline Fe deficiency & Fe deficiency & Fe-deficiency anaemia \\
\hline sTfR $(\mathrm{mg} / \mathrm{l})$ & & & & \\
$\quad$ Median & $3 \cdot 84$ & $6 \cdot 40$ & $9 \cdot 30$ & $13 \cdot 50^{*}$ \\
Interquartile range & $2 \cdot 72-7 \cdot 39$ & $4 \cdot 23-9 \cdot 66$ & $5 \cdot 92-13 \cdot 36$ & $8 \cdot 91-18 \cdot 33$ \\
$n$ & 68 & 45 & 41 & 105 \\
Blood Mn $(\mu \mathrm{g} / \mathrm{dl})$ & & & $3 \cdot 25$ & $4 \cdot 10+$ \\
$\quad$ Median & $2 \cdot 73$ & $2 \cdot 86$ & $2 \cdot 44-4 \cdot 38$ & $3 \cdot 17-5 \cdot 30$ \\
Interquartile range & $1 \cdot 93-3 \cdot 47$ & 46 & 42 & 113 \\
$n$ & 68 & & \\
\hline
\end{tabular}

sTfR, soluble transferrin receptors.

${ }^{*} P<0.001$ overall. Concentration of sTfR was higher in children with Fe-deficiency anaemia compared with those with borderline Fe deficiency or normal Fe status (both $P<0.05$ ). Concentration of STfR was higher in children with Fe deficiency and borderline Fe deficiency compared with those of normal iron status $(P<0.05)$.

$+P<0.01$ overall. Blood Mn was higher in children with Fe-deficiency anaemia and Fe deficiency compared with those with normal Fe status $(P<0 \cdot 01)$.

Table 4 Haematological parameters, presented as means and standard deviations, in children of normal iron status $(n 68)$, borderline iron deficiency ( $n$ 46), iron deficiency $(n 42)$ and iron-deficiency anaemia $(n 113)$ : children $(n 269)$ aged $6-60$ months from low-income families, Karachi, Pakistan

\begin{tabular}{|c|c|c|c|c|c|c|c|c|c|}
\hline \multirow[b]{2}{*}{ Haematological index } & \multicolumn{2}{|c|}{ Normal Fe status } & \multicolumn{2}{|c|}{ Borderline Fe deficiency } & \multicolumn{2}{|c|}{ Fe deficiency } & \multicolumn{2}{|c|}{ Fe-deficiency anaemia } & \multirow[b]{2}{*}{$P$ value } \\
\hline & Mean & SD & Mean & SD & Mean & SD & Mean & SD & \\
\hline $\mathrm{RBC}\left(\times 10^{12} / \mathrm{l}\right)$ & $4 \cdot 6$ & $0 \cdot 88$ & $4 \cdot 7$ & 0.59 & $4 \cdot 8$ & 0.63 & $4 \cdot 6$ & $0 \cdot 76$ & 0.424 \\
\hline WBC $\left(\times 10^{3} / \mu l\right)$ & $12 \cdot 8$ & 3.34 & $10 \cdot 8$ & $3 \cdot 04$ & $12 \cdot 4$ & $5 \cdot 21$ & $13 \cdot 4$ & $6 \cdot 47$ & 0.033 \\
\hline Haematocrit (\%) & $31 \cdot 8$ & $5 \cdot 41$ & $30 \cdot 6$ & $3 \cdot 35$ & $34 \cdot 5$ & $3 \cdot 46$ & $27 \cdot 7$ & $4 \cdot 81$ & 0.001 \\
\hline MCV (fl) & $70 \cdot 9$ & $8 \cdot 88$ & $64 \cdot 4$ & $8 \cdot 45$ & $71 \cdot 5$ & $6 \cdot 92$ & $60 \cdot 3$ & $9 \cdot 43$ & 0.001 \\
\hline $\mathrm{Hb}(\mathrm{g} / \mathrm{dl})$ & $10 \cdot 7$ & 0.23 & $9 \cdot 9$ & $0 \cdot 20$ & $11 \cdot 9$ & $0 \cdot 10$ & $8 \cdot 5$ & $0 \cdot 16$ & 0.001 \\
\hline $\mathrm{MCH}(\mathrm{pg})$ & $23 \cdot 7$ & 3.56 & $21 \cdot 1$ & $3 \cdot 59$ & $23 \cdot 7$ & $2 \cdot 99$ & $18 \cdot 7$ & 3.55 & 0.001 \\
\hline $\mathrm{MCHC}(\%)$ & $33 \cdot 0$ & $1 \cdot 70$ & $32 \cdot 3$ & $2 \cdot 04$ & $33 \cdot 3$ & $1 \cdot 68$ & $30 \cdot 9$ & $2 \cdot 21$ & 0.001 \\
\hline $\mathrm{Fe}(\mu \mathrm{g} / \mathrm{dl})$ & $66 \cdot 5$ & 4.69 & $26 \cdot 4$ & $2 \cdot 21$ & $48 \cdot 9$ & $3 \cdot 49$ & 34.9 & $2 \cdot 20$ & 0.001 \\
\hline Ferritin $(\mu \mathrm{g} / \mathrm{l})$ & $32 \cdot 2$ & $2 \cdot 68$ & $21 \cdot 9$ & 2.08 & $6 \cdot 8$ & 0.44 & $4 \cdot 7$ & 0.25 & 0.001 \\
\hline Transferrin saturation (\%) & $18 \cdot 9$ & 1.04 & $5 \cdot 9$ & $0 \cdot 34$ & $13 \cdot 4$ & 0.99 & $7 \cdot 8$ & $0 \cdot 84$ & 0.001 \\
\hline
\end{tabular}

$\mathrm{RBC}$, red blood cell count; $\mathrm{WBC}$, white blood cell count; $\mathrm{MCV}$, mean cell volume; $\mathrm{MCH}$, mean cell haemoglobin; $\mathrm{MCHC}$, mean cell haemoglobin concentration.

\section{Haematological parameters of children according to Fe status}

Most haematological parameters and indices of Fe status showed a significant relationship $(P<0 \cdot 001)$ in children with different Fe statuses (Table 4). However, there was no significant difference in RBC among children according to Fe status.

\section{Discussion}

The concentrations of blood $\mathrm{Mn}$ in children of normal Fe status found in the present study agree with those published recently for children from Hyderabad in Pakistan, where blood Mn concentrations of 2.95 (SD 0.75) $\mu \mathrm{g} / \mathrm{dl}$ ( $n$ 186) were reported in male and $3 \cdot 12(\mathrm{SD} 0 \cdot 53) \mu \mathrm{g} / \mathrm{dl}$ 
( $n$ 174) in female children 3-7 years of age ${ }^{(15)}$. These values in Pakistan are higher than the value of $1 \cdot 28$ (SD 0.37) $\mu \mathrm{g} / \mathrm{dl}$ ( $n$ 95) reported in 10-year-old Bangladeshi children $^{(16)}$. Indeed, these values are higher than the reference range for blood $\mathrm{Mn}$ of $0 \cdot 4-1 \cdot 2 \mu \mathrm{g} / \mathrm{dl}$ quoted in the $\mathrm{UK}^{(17)}$. In our study the mean concentration of blood $\mathrm{Mn}$ in children of normal Fe status and the mean of all children are higher than the action limit of $2 \cdot 0 \mu \mathrm{g} / \mathrm{dl}$ for blood Mn quoted by the SupraRegional Assay Service for Trace Elements in the UK. Concentrations of blood Mn above the action limit can be treated using EDTA chelation therapy which increases urinary excretion of $\mathrm{Mn}$, thereby reducing blood Mn concentrations ${ }^{(18)}$. Previous studies in other parts of the world such as Bangladesh have demonstrated increased Mn content of drinking water and suggested that this may cause intellectual impairment in children ${ }^{(16)}$. There is limited information on Mn content of drinking water in Pakistan but at least one study conducted in the Southern Sindh region of Pakistan reported water Mn levels within limits posed by the $\mathrm{WHO}^{(19)}$. There has been concern with use of the fuel additive methylcyclopentadienyl manganese tricarbonyl (MMT), which releases Mn as airborne sulfates and phosphates ${ }^{(20)}$. However, other studies have not been able to demonstrate an increase in environmental or blood $\mathrm{Mn}$ with use of $\mathrm{MMT}^{(21)}$. Another possible source of increased blood $\mathrm{Mn}$ in young children is from the mother's milk, particularly if they are residents of Mn-contaminated areas. However, the most likely source of $\mathrm{Mn}$ pollution is industrial as there are a large number of industries in Karachi. These include the steel and metallurgy industries, chemical refineries, and pesticides, electronics and pharmaceutical industries, in addition to automobile and battery repair workshops. However, the precise source of this $\mathrm{Mn}$ in Karachi is not known.

In the current study, children were classified into different groups of Fe status using WHO criteria and supported by sTfR measurements. The WHO criteria included measurement of serum ferritin, which is a good indicator of $\mathrm{Fe}$ deficiency in the early stages. It also reflects stored $\mathrm{Fe}$ which is the first to decline during a deficiency. However, ferritin measurements have to be interpreted with caution as it is an acute-phase reactant that increases during inflammation. Therefore CRP measurements are necessary to exclude individuals with inflammatory conditions ${ }^{(22)}$. Measurements of $\mathrm{Hb}, \mathrm{MCV}$ and $\mathrm{MCH}$ are good indicators of severe or Fe-deficiency anaemia. Measurements of sTfR represent the functional Fe compartment, are best for detection of early Fe deficiency and are not influenced by inflammatory conditions $^{(23)}$. Thus our approach of using both WHO criteria and sTfR measurements provides a more robust determination of Fe status.

Blood Mn concentrations were higher in children with Fe-deficiency anaemia and this may be due to increased absorption of $\mathrm{Mn}$ in the gastrointestinal tract during dietary Fe deficiency. Indeed, it has been demonstrated that both $\mathrm{Fe}$ and $\mathrm{Mn}$ compete for the same transporter, i.e. DMT1, thus a deficiency in Fe causes increased transport of Mn not only into the blood but also across the blood-brain barrier $^{(24)}$. Indeed Fe-deficiency anaemia is associated with increased expression of duodenal DMT1 ${ }^{(25)}$. During lack of dietary Fe, there may be increased uptake of Mn instead; hence the high blood Mn concentrations in children suffering from Fe-deficiency anaemia.

Young children aged 18-24 months often suffer from Fe deficiency and this may account for the higher concentrations of blood $\mathrm{Mn}$ in this age group of children. The high incidence of $\mathrm{Fe}$ deficiency in these children is because they are often weaned on to cow's milk after 12 months of age, which contains insufficient Fe. Another reason for Fe deficiency is lack of consumption of Fe-rich foods such as red meat in children of low socio-economic status. Furthermore, they may start to consume foods such as chapatti that contain phytates which are known to reduce absorption of dietary $\mathrm{Fe}$, thus leading to $\mathrm{Fe}$ deficiency ${ }^{(26)}$. This should allow for greater absorption of $\mathrm{Mn}$ as it competes with Fe. However, this process is complicated by the fact that Mn too is chelated by phytates although the extent of this relative to Fe is unclear.

The major target for Mn toxicity is the brain, where it deposits primarily in the globus pallidus but also in the nigra para reticularis. Subsequently, $\mathrm{Mn}$ is also deposited in other areas such as the striatum, pineal gland olfactory bulb and substantia nigra pars compacta ${ }^{(12)}$. MRI can be used to monitor deposition of $\mathrm{Mn}$ in the brain ${ }^{(12)}$. Deposition of $\mathrm{Mn}$ in the brain produces neurotoxicity and symptoms similar to Parkinson's disease. However the two are distinct in the sites affected and the clinical symptoms produced ${ }^{(18)}$. Although manganism has only been shown in adults, the effect of Mn toxicity on child development and behaviour is of concern in young children as they absorb more Mn from the diet compared with adults ${ }^{(27)}$. Thus children are more likely to suffer Mn toxicity if they are Fe deficient. Indeed, toxic effects of $\mathrm{Mn}$ on intellectual impairment have been reported in 6-13-year-old children who were exposed to Mn from tap water ${ }^{(28)}$. A tenfold increase of $\mathrm{Mn}$ in tap water was associated with a decline in intelligence quotient of 2.4 points in these children. Another study in children aged 1-2 years showed that Mn was an essential nutrient but toxic at high levels in young children, affecting neurodevelopment ${ }^{(29)}$.

\section{Conclusion}

Childhood Fe deficiency is a common nutritional problem in Pakistan; it is associated with poor dietary intake of $\mathrm{Fe}$ and affects children from families of lower socioeconomic status. The present study reports for the first time high concentrations of blood Mn particularly in 
children with Fe deficiency residing in Karachi. The consequences of chronic exposure to $\mathrm{Mn}$ are severe and thus the sources of Mn pollution need to be identified. There is therefore a need not only to reduce environmental Mn pollution, but also to consider approaches such as Fe fortification of foods aimed at correcting Fe deficiency in young children.

\section{Acknowledgements}

Sources of funding: The authors are grateful to the Nestle Foundation for a project grant which allowed them to undertake the study. Conflict of interest: None of the authors report any conflict of interest. Authors' contributions: N.A. and M.A.R. designed the study, analysed the data and wrote the paper. B.R. performed the research and analysed the data. Acknowledgements: The authors are grateful to Dr Arshalooz Rehman and Dr Ghulam Murtaza for their assistance with recruitment of patients and collection of blood specimens in Karachi and to Dr Andrew Blann from the City Hospital, Birmingham, UK for his help with the statistical analysis.

\section{References}

1. Huma N, Ur-Rehman S, Anjum FM et al. (2007) Food fortification strategy - preventing iron deficiency anemia: a review. Crit Rev Food Sci Nutr 47, 259-265.

2. Kordas K (2010) Iron, lead, and children's behavior and cognition. Annu Rev Nutr 30, 123-148.

3. Lynch SR \& Stoltzfus DS (2003) Iron and ascorbic acid: proposed fortification levels and recommended iron compounds. J Nutr 133, issue 9, 2978S-2984S.

4. Gunshin H, Mackenzie B, Berger UV et al. (1997) Cloning and characterization of a mammalian proton-coupled metal-ion transporter. Nature 388, 482-488.

5. Riojas-Rodriguez H, Solis-Vivanco R, Schilmann A et al (2010) Intellectual function in Mexican children living in a mining area and environmentally exposed to manganese. Environ Health Perspect 118, 1465-1470.

6. Donaldson J (1987) The physiopathologic significance of manganese in brain: its relation to schizophrenia and neurodegenerative disorders. Neurotoxicology $\mathbf{8}$, 451-462.

7. Mergler D (1996) Manganese: the controversial metal. At what levels can deleterious effects occur? Can J Neurol Sci 23, 93-94.

8. Alves G, Thebot J, Tracqui A et al. (1997) Neurological disorders due to brain manganese deposition in a jaundiced patient receiving long-term parenteral nutrition. $J$ Parenter Enteral Nutr 21, 41-45.

9. Ross C, O'Reilly DSJ, McKee R et al. (2006) Potentially clinically toxic concentrations of whole blood manganese in a patient fed enterally with a high tea consumption. Ann Clin Biochem 43, 226-228.

10. Mena I, Horiuchi K, Burke K et al. (1969) Chronic manganese poisoning: individual susceptibility and absorption of iron. Neurology 19, 1000-1006.
11. Rossander-Hulten L, Brune M, Sandstrom B et al. (1991) Competitive inhibition of iron absorption by manganese and zinc in humans. Am J Clin Nutr 54, 152-156.

12. Fitsanakis VA, Zhang N, Avison MJ et al. (2006) The use of magnetic resonance imaging (MRI) in the study of manganese neurotoxicity. Neurotoxicology 27, 798-806.

13. Davidson L, Lonnerdal B, Sandstrom B et al. (1989) Identification of transferrin as the major plasma protein carrier for manganese introduced orally or intravenously or after in vitro addition in the rat. J Nutr 119, 1461-1464.

14. Kim Y, Park JK, Choi Y et al. (2005) Blood manganese concentration is elevated in iron deficiency anemia patients, whereas globus pallidus signal intensity is minimally affected. Neurotoxicology 26, 107-111.

15. Afridi HI, Kazi TG, Kazi N et al. (2011) Chromium and manganese levels in biological samples of normal and night blindness children of age groups (3-7) and (8-12) years. Biol Trace Elem Res 143, 103-115.

16. Wasserman GA, Liu X, Parvez F et al. (2006) Water manganese exposure and children's intellectual function in Araihazar, Bangladesh. Environ Health Perspect 114, 124-129.

17. Taylor A (1996) Detection and monitoring of disorders of essential trace elements. Ann Clin Biochem 33, 486-510.

18. Crossgrove J \& Zheng W (2004) Manganese toxicity upon overexposure. NMR Biomed 17, 544-553.

19. Memon M, Soomro MS, Akhtar MS et al. (2011) Drinking water quality assessment in Southern Sindh (Pakistan). Environ Monit Assess 177, 39-50.

20. Pfeiffer GD, Roper JM, Dorman D et al. (2004) Health and environmental testing of manganese exhaust products from use of methylcyclopentadienyl manganese tricarbonyl in gasoline. Sci Total Environ 334-335, 397-408.

21. Gulson B, Mizon K, Taylor A et al. (2006) Changes in manganese and lead in the environment and young children associated with the introduction of methylcyclopentadienyl manganese tricarbonyl in gasoline - preliminary results. Environ Res J 100, 100-114.

22. Wang W, Knovich MA, Coffman LG et al. (2010) Serum ferritin: past, present and future. Biochim Biophys Acta 1800, 760-769.

23. Beguin Y (2003) Soluble transferrin receptors for the evaluation of erythropoiesis and iron status. Clin Chim Acta 329, 9-22.

24. Fitsanakis VA, Zhang N, Garcia S et al. (2010) Manganese $(\mathrm{Mn})$ and iron $(\mathrm{Fe})$ : interdependency of transport and regulation. Neurotoxicol Res 18, 124-131.

25. Byrnes V, Barrett S, Ryan E et al. (2002) Increased duodenal DMT-1 expression and unchanged HFE mRNA in HFE-associated hereditary haemochromatosis and iron deficiency. Blood Cells Mol Dis 29, 251-260.

26. Tupe R, Chiplonkar SA \& Kapadia-Kundu N (2009) Influence of dietary and socio-economic factors on the iron status of married adolescent girls from Indian urban slums. Int J Food Sci Nutr 60, 51-59.

27. Winder BS (2010) Manganese in the air: are children at greater risk than adults? J Toxicol Environ Health 73, 156-158.

28. Bouchard MF, Sauve S, Barbeau B et al. (2011) Intellectual impairment in school-age children exposed to manganese from drinking water. Environ Health Perspect 119, $138-143$.

29. Claus Henn B, Ettinger AS, Schwartz J et al. (2010) Early postnatal blood manganese levels and children's neurodevelopment. Epidemiology 21, 433-439. 